\title{
Democracy and case fatality rate of COVID-19 at early stage of pandemic: a multicountry study
}

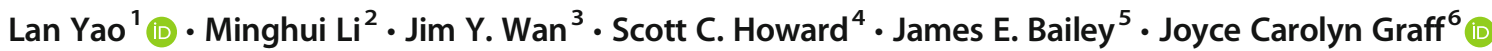

Received: 30 July 2021 / Accepted: 26 August 2021 / Published online: 7 September 2021

(C) The Author(s), under exclusive licence to Springer-Verlag GmbH Germany, part of Springer Nature 2021

\begin{abstract}
Many studies have evaluated factors that influence the course of the COVID-19 pandemic in different countries. This multicountry study assessed the influence of democracy and other factors on the case fatality rate of COVID-19 during the early stage of the pandemic. We accessed the World Health Organization, World Bank, and the Democracy Index 2019 databases for data from the 148 countries. Multiple analyses were conducted to examine the association between the Democracy Index and case fatality rate of COVID-19. Within 148 countries, the percentage of the population aged 65 years and above $(p=0.0193)$, and health expenditure as a percentage of $\operatorname{GDP}(p=0.0237)$ were positively associated with countries' case fatality rates. By contrast, hospital beds per capita helped to reduce the case fatality rates. In particular, the Democracy Index was positively associated with case fatality rates in a subgroup of 47 high-income countries. This study suggests that enhancing the health system with increased hospital beds and healthcare workforce per capita should reduce case fatality rate. The findings suggest that a higher Democracy Index is associated with more deaths from COVID-19 at the early stage of the pandemic, possibly due to the decreased ability of the government.
\end{abstract}

Keywords COVID-19 $\cdot$ Comorbidity $\cdot$ Case fatality rate $\cdot$ Democracy $\cdot$ Health expenditure $\cdot$ Healthcare workforce

\section{Background}

COVID-19 poses a major global threat to humankind, inflicting devastating consequences on the public health, politics, and economy of many countries (Greer et al. 2020). The World Health Organization (WHO) announced that the novel coronavirus disease 2019 (COVID-19) outbreak was a public health emergency of international concern on January 30 ,

Responsible Editor: Lotfi Aleya

Lan Yao

lyao5@uthsc.edu

Joyce Carolyn Graff

jgraff@uthsc.edu

Minghui Li

mli54@uthsc.edu

Jim Y. Wan

jwan@uthsc.edu

Scott C. Howard

showard5@uthsc.edu

James E. Bailey

jeb@uthsc.edu
2020 (World Health Organization 2020a). On March 11, 2020, the COVID-19 outbreak officially became a pandemic (Bavel et al. 2020), subsequently causing 191,686,787 confirmed cases and 4,112,533 deaths worldwide as of July 20, 2021 (Johns Hopkins Coronavirus Resource Center 2021). The number of infections (as of July 20, 2021) are 23,677 times more than the infections that occurred during the previous outbreak of severe acute respiratory syndrome (SARS)
1 Health Outcomes and Policy Research, College of Graduate Health Sciences, University of Tennessee Health Science Center, 750 Adams Ave \#1001, Memphis, TN 38163, USA

2 Minghui Li, College of Pharmacy, University of Tennessee Health Science Center, Memphis, TN 38163, USA

3 Jim Y. Wan, College of Medicine, University of Tennessee Health Science Center, Memphis, TN 38163, USA

4 Scott C. Howard, College of Nursing, University of Tennessee Health Science Center, Memphis, TN 38163, USA

5 James E. Bailey, College of Medicine, University of Tennessee Health Science Center, Memphis, TN 38163, USA

6 College of Nursing, University of Tennessee Health Science Center, 874 Union Avenue, Memphis, TN 38163, USA 
from 2002 to 2003 (Fidler 2004). In addition, according to the COVID-19 Dashboard managed by the Center for Systems Science and Engineering (CSSE) at Johns Hopkins University, the number of confirmed cases and deaths related to COVID-19 varies dramatically across countries, which reflects findings that cannot be explained by superficial analyses because the pandemic started earlier in some states and regions than in others. In general, countries that score higher on the Democracy Index have healthier populations (Besley and Kudamatsu 2006; Safaei 2006), longer life expectancy (Franco et al. 2004; Mackenbach et al. 2013), lower maternal and infant mortality (Shandra et al. 2010), and higher expenditures for healthcare services (Blum et al. 2021). The rationale that democracy could improve health status is easy to understand. Firstly, when enforced through regular, free, and fair elections, democratic countries have a greater incentive than autocratic countries to provide welfare, health-related resources, and services to most of the citizens (Besley and Kudamatsu 2006). In addition, democratic countries are more communicative with a broader set of interest groups, enjoy more freedom of media and press, and might be more active in utilizing the feedback from interest groups to enhance national public health programs. On the contrary, autocratic countries reduce political competition and access to information, which might deter constituent feedback and responsive governance (Karabulut et al. 2021). However, it has not been clear whether assessments of democracy in life expectancy and maternal and infant health are generalizable to infectious diseases, particularly a pandemic, at the early stage, which needs massive healthcare delivery, medical resources, healthcare professionals, and the ability to enforce public health measures such as quarantine, mask-wearing, pool testing, and other potential measures of preventing disease transmission (Gu et al. 2020).

Many studies have explored population health, quarantine, medical, and economic measures related to COVID-19, but few publications report on whether democracy is related to COVID-19 mortality worldwide, especially for the disease outbreak at an early stage (Driggin et al. 2020; Pan et al. 2020; Pareek et al. 2020). Karabulut and colleagues (Karabulut et al. 2021) found that democracy is positively related to infections. In 27 European countries, the Democracy Index (DI) and the political system (full democracy vs. authoritarian) were statistically correlated with mortality, where higher scores on the Democracy Index were associated with higher mortality rates $(p=0.003)$ (Mazzucchelli et al. 2020).

Two theories suggest relevant domains to explore the relationship between political systems and health. Political epidemiology theory developed by Arthur Brownlea suggests that the role of politics in solving health issues rivals that of medical interventions and epidemiological measures (Brownlea 1981). Social epidemiology proposes that the distribution of strengths and weaknesses in society echoes the distribution of disease and health. The theory aims to identify societal features that influence the natural history of diseases and their mechanisms (Honjo 2004).

This study explores the association between democracy and the case fatality rate of COVID-19 at the early stage of a pandemic based on global databases that allow controlling for the effect of other risk factors. These risk factors include the percentage of the population ages 65 and above, hospital beds per capita, health expenditure as a percentage of GDP, the proportion of non-communicable diseases (NCD) caused deaths of total deaths, healthcare workforce per capita, and population density. Notably, this study evaluates a new predictor seldom used in health outcomes research. The DI may correlate with the ability of governments to enforce mandated public health measures during a pandemic (Economist Intelligence Unit 2020b). Further, the DI approximates the extent to which a government can mandate the behavior of its citizens and how the citizens react to the government (Grossman et al. 2020). Mitigation of infectious disease transmission profoundly depends on citizens' attitude, behavior, response, and mobility (Grossman et al. 2020; Kraemer et al. 2020; Yan et al. 2020). The study team hypothesized that the DI score is negatively associated with the case fatality rate of the COVID-19.

\section{Methods}

\section{Data collection}

\section{COVID-19 confirmed cases, deaths, and tests performed}

The study team collected data of cumulative confirmed COVID-19 cases and deaths from the WHO open data repository (https://covid19.who.int/) accessed on October 25, 2020, a date chosen to reflect the early period of the pandemic, when therapeutics were limited and no vaccines had been approved (World Health Organization 2020b). In addition, the team collected the total number of tests and tests per 1,000,000 population from the COVID-19 Data Repository managed by the Center for Systems Science and Engineering(CSSE) (https://github.com/CSSEGISandData/COVID-19) at Johns Hopkins University on October 25, 2020 (Johns Hopkins Coronavirus Resource Center 2020). The case fatality rate (CFR) is defined as the number of individuals who died of COVID-19 divided by the number of confirmed cases over a certain period of time (Kelly and Cowling 2013a).

\section{Democracy index}

The dataset of the Economist Intelligence Unit's Democracy Index 2019 (https://www.eiu.com/n/campaigns/democracy- 
index-2019/) provided a snapshot of democracy worldwide and nearly covered the global population (Economist Intelligence Unit 2020b). The DI uses Economist Intelligence Unit (EIU) data to evaluate the quality of democracy as a composite score ranging from zero to ten. The DI comprises 60 different aspects of society and includes all aspects of political and civic life such as universal suffrage for adults, voter participation, perception of human rights protection, and freedom to establish organizations and parties. The DI2019 has five subscales that address the following: electoral process and pluralism, civil liberties, the functioning of government, political participation, and political culture. Data is obtained by experts' assessment and scores are based on a range of indicators within these five categories and the composite score is calculated as the mean of the five categories. The DI is scored from zero to ten and grouped into four clusters labeled full democracy (scored 8.0-10.0), flawed democracy (scored 6.0-7.9), hybrid regime (scored 4.0-5.9), and authoritarian regime (scored 0.0-3.9). In addition, the study team stratified countries as low-income, lower-middle-income, higher-middle-income, and high-income based on world bank definitions in 2020 (Espen Beer Prydz 2019). DI data were collected from the Economist Intelligence Unit database 2019 (Economist Intelligence Unit 2020a).

\section{Covariates}

Older age and presence of comorbidities are major risk factors for COVID-19 severity and mortality (Albitar et al. 2020, Sanyaolu et al. 2020). The percentage of deaths caused by non-communicable disease of the total deaths is an indicator for population who is more likely to be infected by COVID-19 (Kluge et al. 2020). Healthcare workforce may also impact COVID-19 outcomes and was modeled as the number of medical doctors, nurses, and midwives per 10,000 population (Adams and Walls 2020). Population density (population per square kilometer) (Coşkun et al. 2021), hospital beds per 1000 population (Sen-Crowe et al. 2021), health expenditure as a percentage of gross domestic product (GDP) in US dollars (Alhassan et al. 2020), and the percentage of population ages 65 and above (Ho et al. 2020) were taken into account as covariates and collected from the World Bank (https://www. worldbank.org/en/understanding-poverty) and WHO databases (World Bank 2020, World Health Organization 2020c).

\section{Data selection and preparation}

The study team excluded countries that reported less than 2000 confirmed cases of COVID-19 and any country that had missing data in terms of any variable. The sample size for main analyses was 148 countries while data from the 47 high-income countries were analyzed separately.

\section{Statistical analysis}

Descriptive statistics, mean, median, standard deviation, and interquartile range (IQR) were provided for all predictors (Table 1). The study team implemented multiple linear regression and negative binomial regression analyses. Both are widely applied to examine the association between potential explanatory factors and the cases, deaths, and case fatality rate of COVID-19 (Alhassan et al. 2020). The outcome variable was chosen as the case fatality rate, which was calculated as the rate of cumulative deaths divided by cumulative confirmed cases of COVID-19 (Kelly and Cowling 2013b). Due to the highly skewed data across countries, log transformation was performed prior to multiple linear regression analysis. The main predictor variable was the DI score, and the outcome variable was the case fatality rate. A series of variables were included as potential confounders and controlled for in the regression model, including the percentage of the population ages 65 and above, hospital beds per 10,000 population, population density, healthcare workforce per capita, health expenditure as a percentage of GDP, and the percentage of deaths caused by non-communicable disease of total deaths. Multiple linear regression was conducted on two levels. The first set of analyses including the whole dataset of 148 countries and a second set of analyses of the 47 high-income countries was stratified by the four country income levels specified by the World Bank (World Bank 2020; World Health Organization 2020c). The team employed statistical software SAS (version 9.4) and the level of significance was set at $\alpha=0.05$.

\section{Results}

\section{Variables summary}

The initial analysis showed that the means of cumulative confirmed cases, cumulative deaths, the case fatality rate, population density, the percentage of population ages 65 and above, health expenditure as a percentage of GDP, the percentage of deaths caused by non-communicable diseases of total deaths, healthcare workforce per 10,000 population, hospital beds per 1000 population, and DI were $135,996.00$, $4325.00,2.31 \%, 146.75,9.35 \%, 6.54 \%, 68.88 \%, 63.02$, 2.89 , and 5.53 , respectively (Table 1 ).

\section{Whole group analysis}

\section{Multiple linear regression}

For the first level, model 1 included the whole dataset of 148 countries. The $R^{2}$ for model 1 was 0.1479 (Table 2). 
Table 1 Descriptive statistics of variables $(N=148)$

\begin{tabular}{lllll}
\hline Variables & Mean & Median & Standard deviation & Interquartile range \\
\hline Population ages 65 and above $^{\mathrm{a}}$ & 9.35 & 6.81 & 6.76 & 11.86 \\
Population density $^{\mathrm{b}}$ & 146.75 & 80.28 & 248.65 & 111.00 \\
Health expenditure of GDP $^{\mathrm{c}}$ & 6.54 & 6.43 & 2.41 & 3.59 \\
NCD-caused deaths $^{\mathrm{d}}$ & 68.88 & 76.60 & 22.78 & 44.25 \\
Healthcare workforce $^{\mathrm{e}}$ & 63.02 & 44.39 & 56.34 & 82.01 \\
Hospital beds $^{\mathrm{f}}$ & 2.89 & 2.10 & 2.44 & 3.15 \\
Democracy Index $^{\mathrm{g}}$ & 5.53 & 5.78 & 2.24 & 3.84 \\
Cumulative cases $^{\mathrm{h}}$ & $135,996.00$ & $34,470.00$ & $252,530.00$ & $115,870.00$ \\
Cumulative deaths $^{\mathrm{i}}$ & $4,325.00$ & 491.50 & $10,806.00$ & 2150.00 \\
Tests per 1,000,000 people & $148,137.90$ & $71,763.50$ & $226,368.00$ & $180,103.00$ \\
Case fatality rate $^{\mathrm{j}}$ & 2.31 & 1.94 & 1.72 & 1.85 \\
\hline
\end{tabular}

${ }^{\text {a }}$ Percentage of the population ages 65 and above

${ }^{\mathrm{b}}$ Population per $\mathrm{km}^{2}$ of the country's surface area

${ }^{\mathrm{c}}$ Health expenditure as a percentage of the gross domestic product

${ }^{\mathrm{d}}$ Percentage of deaths caused by non-communicable diseases of total deaths

${ }^{\mathrm{e}}$ Total number of medical doctors, nurses, and midwives per 10,000 population

${ }^{\mathrm{f}}$ Number of hospital beds per 1000 population

${ }^{\mathrm{g}}$ Democracy Index score $(0-10)$

h,i The starting points for cumulative cases and deaths were the confirmed days on which the $50^{\text {th }}$ case and $50^{\text {th }}$ death occurred in each country

${ }^{\mathrm{j}}$ Ratio of cumulative deaths from COVID-19 to cumulative cases of COVID-19 (expressed as a percentage)
The model is formulated as:

$$
\begin{aligned}
Y= & 0.00282+0.0039 \mathrm{X} 1+0.0006 \mathrm{X} 2+0.0039 \mathrm{X} 3 \\
& +0.0008 \mathrm{X} 4-0.001 \mathrm{X} 5-0.0028 \mathrm{X} 6-0.0004 \mathrm{X} 7
\end{aligned}
$$

$Y$ is dependent variable, log transformation of case fatality rate. X1 is population ages 65 and above (\% of total population). $\mathrm{X} 2$ is the population density. $\mathrm{X} 3$ is the health expenditure of GDP. X4 is non-communicable diseases caused deaths (\% of total deaths). X5 is healthcare workforce per capita. X6 is hospital beds per capita. X7 is the Democracy Index. $\beta 0$ is 0.00282 which is the $y$-intercept when all other parameters are set to zero.

Hospital beds per 1000 population were negatively correlated with the case fatality rate of COVID-19 $(\beta=-0.00282$; $p<0.05$ ). For this model, one could conclude that a $1 \%$ increase in the hospital beds per 1000 population would yield a $0.00282 \%$ decrease in the case fatality rate of COVID- 19 .
Table 2 Multiple Linear Regression Results of the Association Between Predictors and Case Fatality Rate of COVID-19 $(\mathrm{N}=148)$

\begin{tabular}{lll}
\hline Variables & $\begin{array}{l}\text { Model 1 } \\
\text { Parameter estimate }(\beta)\end{array}$ & $\begin{array}{l}\left(R^{2}=0.1479\right) \\
P \text { value }\end{array}$ \\
\hline Population ages 65 and above $^{\mathrm{a}}$ & 0.0039 & 0.0193 \\
Population density $^{\mathrm{b}}$ & 0.0006 & 0.1168 \\
Health expenditure as a percentage of GDP $^{\mathrm{c}}$ & 0.0039 & 0.0237 \\
NCD-caused deaths $^{\mathrm{d}}$ & 0.0008 & 0.7720 \\
Healthcare workforce $^{\mathrm{e}}$ & -0.0010 & 0.2958 \\
Hospital beds $^{\mathrm{f}}$ & -0.0028 & 0.0116 \\
Democracy Index $^{\mathrm{g}}$ & -0.0004 & 0.1747 \\
\hline
\end{tabular}

${ }^{\text {a }}$ Percentage of the population ages 65 and above

${ }^{\mathrm{b}}$ Population per $\mathrm{km}^{2}$ of the country's surface area

${ }^{\mathrm{c}}$ Health expenditure as a percentage of the gross domestic product

${ }^{\mathrm{d}}$ Percentage of deaths caused by non-communicable diseases of total deaths

${ }^{\mathrm{e}}$ Total number of medical doctors, nurses, and midwives per 10,000 population

${ }^{\mathrm{f}}$ Number of hospital beds per 1000 population

${ }^{\mathrm{g}}$ Democracy Index score (0-10) 
Conversely, the percentage of the population ages 65 and above was positively associated with the case fatality rate $(\beta$ $=0.00391 ; p<0.05$ ). Also, the health expenditure of the GDP was positively related to the case fatality rate of COVID-19 ( $\beta$ $=0.00397 ; p<0.05$ ).

\section{Negative binomial regression}

Negative binomial regression was used to estimate the association between predictors and counts of cases and deaths of COVID-19 (Tables 3 and 4).

The regression equations for these models are shown below as:

$\log (\mathrm{Yc})=7.6639-0.0668 \mathrm{X} 1-0.0003 \mathrm{X} 2+-0.04420 \mathrm{X} 3+0.0550 \mathrm{X} 4-0.0034 \mathrm{X} 5+0.0698 \mathrm{X} 6+0.1915 \mathrm{X} 7$
$\log (\mathrm{Yd})=3.2351-0.0110 \mathrm{X} 1-0.0010 \mathrm{X} 2+0.0199 \mathrm{X} 3+0.0648 \mathrm{X} 4-0.0079 \mathrm{X} 5-0.0649 \mathrm{X} 6+0.1855 \mathrm{X} 7$

Yc is the counts of confirmed cases of COVID-19. Yd is the counts of deaths due to COVID-19. X1 is population ages 65 and above (\% of total population). X2 is the population density. X3 is the health expenditure of GDP. X4 is noncommunicable diseases (NCD)-caused deaths (\% of total deaths). X5 is healthcare workforce per capita. X6 is hospital beds per capita. X7 is the Democracy Index.

Using these two regression models, we estimate that the percentage of deaths caused by non-communicable diseases has a coefficient of 0.0648 with $\log$ count of deaths due to COVID-19, which is statistically significant. Given one-unit increase of death caused by non-communicable disease, the expected log count of the number of deaths would increase by 0.0648 person. What is more, regression for cases suggests that the percentage of NCDcaused deaths has a significant coefficient of 0.0550 . We expect that for each one-unit increase in NCD-caused deaths of total deaths, the log count of the cases increases by 0.0550 . Also, the Democracy Index has a significant coefficient of 0.1915 which shows that for each one-unit increase in DI, the log count of the cases increases by 0.1915 .

Table 3 Negative binomial regression estimated association between predictors and cases $(N=148)$

\begin{tabular}{lll}
\hline Variables & Odds ratio & 95\% CI \\
\hline Population ages 65 and above $^{\mathrm{a}}$ & 0.9353 & $(0.8535,1.0251)$ \\
Population density $^{\mathrm{b}}$ & 0.9997 & $(0.9986,1.0007)$ \\
Health expenditure of GDP $^{\mathrm{c}}$ & 1.0565 & $(1.0360,1.0773)$ \\
NCD-caused deaths $^{\mathrm{d}}$ & 0.9568 & $(0.8388,1.0913)$ \\
Healthcare workforce $^{\mathrm{e}}$ & 0.9966 & $(0.9883,1.0051)$ \\
Hospital beds $^{\mathrm{f}}$ & 1.0723 & $(0.9112,1.2618)$ \\
Democracy Index $^{\mathrm{g}}$ & 1.2110 & $(1.0256,1.4299)$ \\
\hline
\end{tabular}

${ }^{\text {a }}$ Percentage of the population ages 65 and above

${ }^{\mathrm{b}}$ Population per $\mathrm{km}^{2}$ of the country's surface area

${ }^{\mathrm{c}}$ Health expenditure as a percentage of the gross domestic product

${ }^{\mathrm{d}}$ Percentage of deaths caused by non-communicable diseases of total deaths

${ }^{\mathrm{e}}$ Total number of medical doctors, nurses, and midwives per 10,000 population

${ }^{\mathrm{f}}$ Number of hospital beds per 1000 population

${ }^{\mathrm{g}}$ Democracy Index score (0-10).

\section{Influence of democracy on the case fatality rate}

Among the 148 countries in this research, $15 \%$ were labeled as full democracy, $31 \%$ as flawed democracy, $24 \%$ as hybrid regime, and $30 \%$ as authoritarian regime countries. Categorized by income levels, $32 \%$ of countries were classified as high-income followed by $28 \%$ higher-middle-income, $24 \%$ lower-middle-income, and 16\% low-income. Box plots demonstrated that cumulative confirmed cases, cumulative deaths, tests per 1,000,000 population, and case fatality rates differed across the four regime types. The variations between countries were significant due to the skewed data and characteristics of countries. The highest confirmed cases appeared in countries within the full democracy regime type, while countries having the least cases were attributed to authoritarian countries. The case fatality rates in full democracy countries were higher than that in most authoritarian and flawed democracy countries. Both lowest confirmed cases and case fatality rate were observed among authoritarian countries (Fig. 1).

Table 4 Negative binomial regression estimated association between predictors and deaths $(N=148)$

\begin{tabular}{lll}
\hline Variables & Odds ratio & $95 \% \mathrm{CI}$ \\
\hline Population ages 65 and above $^{\mathrm{a}}$ & 0.9891 & $(0.8850,1.1054)$ \\
Population density $^{\mathrm{b}}$ & 0.9990 & $(0.9978,1.0002)$ \\
Health expenditure of GDP $^{\mathrm{c}}$ & 1.0669 & $(1.0441,1.0902)$ \\
NCD-caused deaths $^{\mathrm{d}}$ & 1.0201 & $(0.8762,1.1877)$ \\
Healthcare workforce $^{\mathrm{e}}$ & 0.9921 & $(0.9826,1.0018)$ \\
Hospital beds $^{\mathrm{f}}$ & 0.9372 & $(0.7747,1.1338)$ \\
Democracy Index $^{\mathrm{g}}$ & 1.2038 & $(0.9983,1.4514)$ \\
\hline
\end{tabular}

${ }^{\mathrm{a}}$ Percentage of the population ages 65 and above

${ }^{\mathrm{b}}$ Population per $\mathrm{km}^{2}$ of the country's surface area

${ }^{\mathrm{c}}$ Health expenditure as a percentage of the gross domestic product

${ }^{\mathrm{d}}$ Percentage of deaths caused by non-communicable diseases of total deaths

${ }^{\mathrm{e}}$ Total number of medical doctors, nurses, and midwives per 10,000 population

${ }^{\mathrm{f}}$ Number of hospital beds per 1000 population

${ }^{\mathrm{g}}$ Democracy Index score (0-10). 
Figure 2 presents the distribution of current health expenditure of GDP compared side-by-side with four categories of regime type. Full democracy countries invested least in the health sector than the others. Similarly, the percentage of the population ages 65 and above was also the highest in full democracy countries (Fig. 2).

As for the healthcare system, the healthcare workforce in full democracy countries were the highest for distribution of health human resources followed by flawed democracy, authoritarian regime, and hybrid regime. In addition, there were more hospital beds per 1000 population in democratic countries than in authoritarian countries (Fig. 3).

\section{Subgroup analysis}

\section{Multiple linear regression}

The model for the subgroup, 47 high-income countries, is calculated as:

$$
\begin{aligned}
Y= & 0.0382+0.0085 \mathrm{X} 1+0.0002 \mathrm{X} 2 \\
& +0.0068 \mathrm{X} 3-0.0024 \mathrm{X} 4 \\
& +0.0023 \mathrm{X} 5-0.0075 \mathrm{X} 6-0.0019 \mathrm{X} 7
\end{aligned}
$$

$Y$ is the dependent variable, $\log$ transformation of case fatality rate. $\mathrm{X} 1$ is population ages 65 and above (\% of total population). $\mathrm{X} 2$ is the population density. $\mathrm{X} 3$ is the health expenditure of GDP. X4 is NCDcaused deaths (\% of total deaths). X5 is healthcare workforce per capita. X6 is hospital beds per capita. $\mathrm{X} 7$ is the Democracy Index. $\beta 0$ is 0.0382 which is the $y$-intercept when all other parameters are set to zero.

Based on the calculation using the equation above, we obtained the results of association estimation (Table 5). Within 47 high-income countries, hospital beds per 1000 population were negatively correlated with the case fatality rate of COVID-19 ( $\beta=-$ $0.00754 ; p<0.05)$. For the second model, a $1 \%$ increase in the hospital beds per 1000 population yields a $0.00754 \%$ decrease in the case fatality rate of COVID-19. On the contrary, the percentage of population ages 65 and above was also positively associated with the case fatality rate $(\beta=0.00858 ; p<0.05)$. Finally, the Democracy Index was negatively correlated with the case fatality rate of COVID-19 ( $\beta=-$ $0.00192 ; p<0.05)$. However, the effect of health expenditure of GDP did not reach a significant level among high-income countries as shown in model 2.
Fig. 1 The cumulative confirmed cases and deaths of COVID-19, tests per 1,000,000 population, and case fatality rate distribution by regime type. The $x$-axis represents the four types of regimes in the order of

"Authoritarian Regime," "Hybrid Regime," "Flawed Democracy," and "Full Democracy." $Y$-axis units are displayed in parentheses. a $y$-axis indicates the cumulative confirmed cases per $1,000,000$ population. $\mathbf{b} y$-axis indicates the cumulative deaths per 10,000 population. $\mathbf{c} y$-axis indicates the tests per 1,000,000 population. $\mathbf{d}$ $y$-axis indicates the case fatality rate $(\%)$

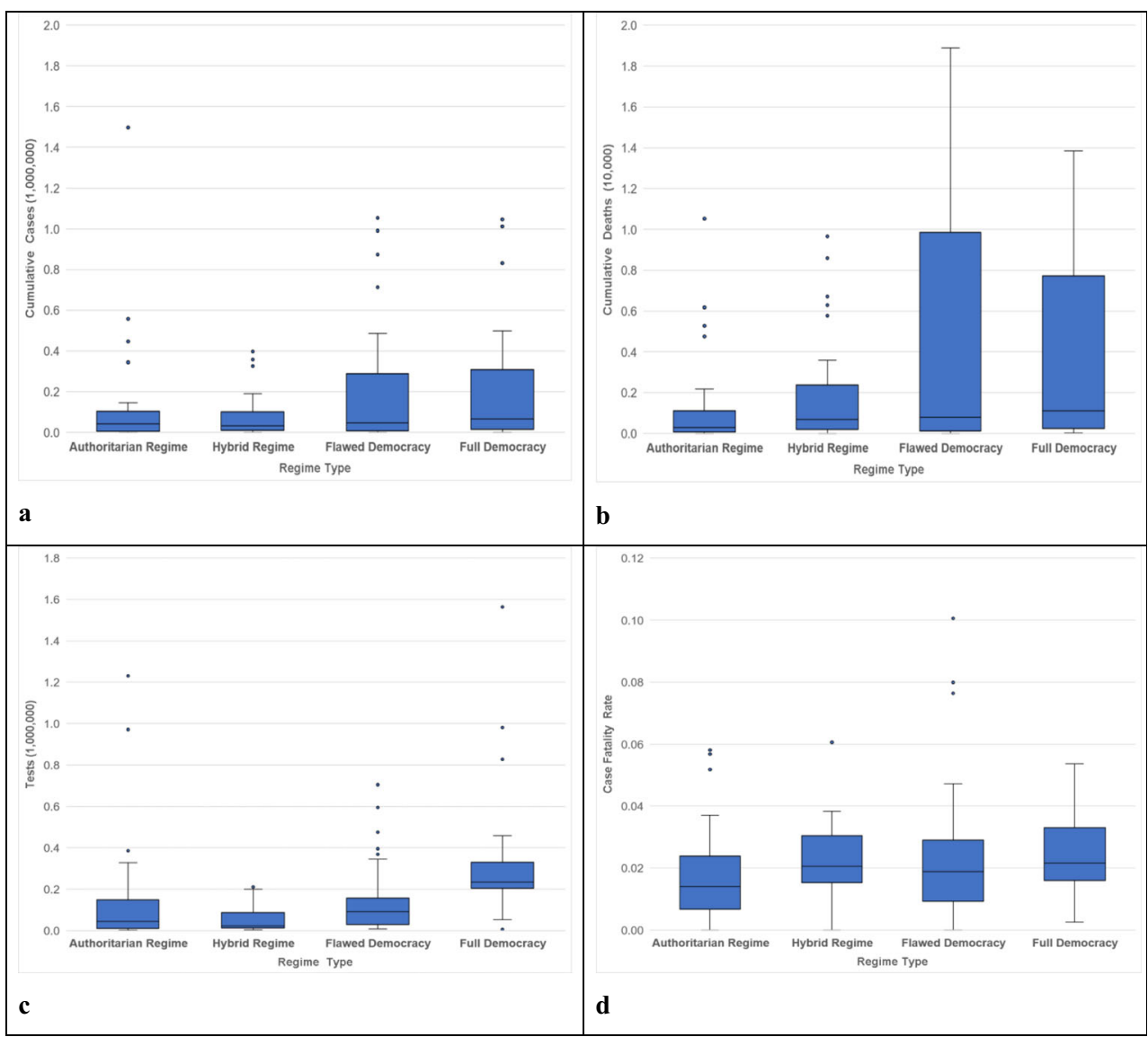


Fig. 2 Health expenditure of GDP and percentage of population ages 65 and above distribution by regime types. a $x$ axis represents the four types of regimes in the order of

"Authoritarian Regime," "Hybrid Regime," "Flawed Democracy," and "Full Democracy," $y$-axis indicates the health expenditure as a percentage of GDP (in US dollars). b $y$-axis indicates the percentage of population ages 65 and above

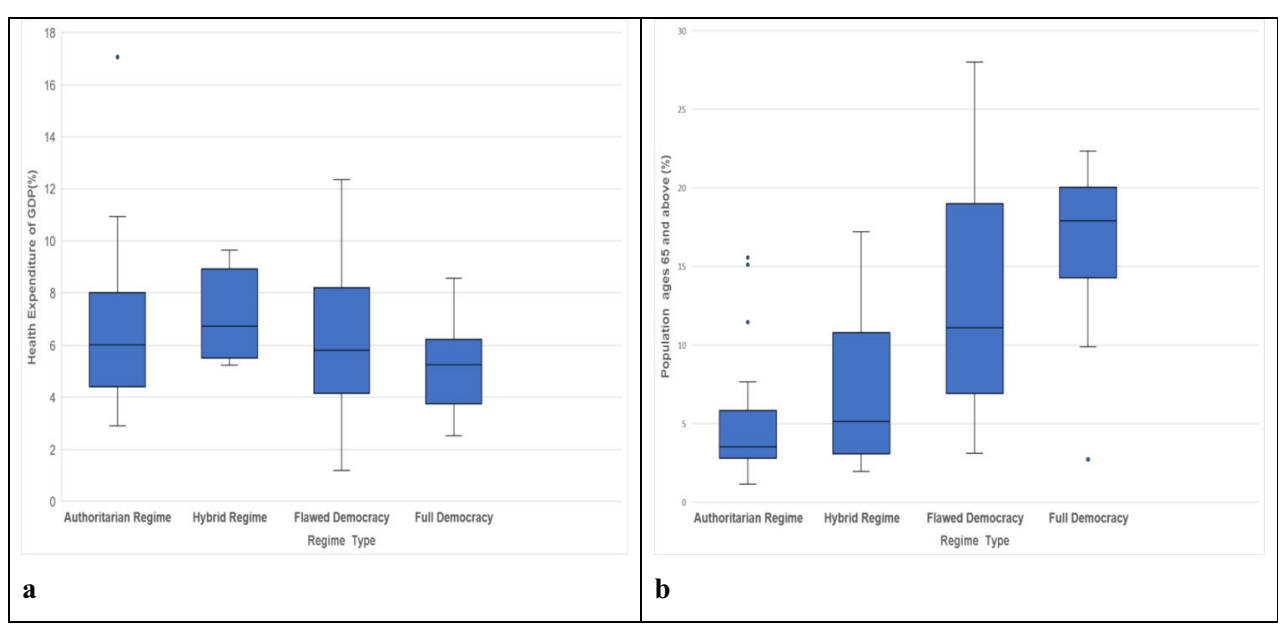

\section{Negative binomial regression}

Negative binomial regression was used to estimate the association between predictors and cases as well as deaths of COVID-19 (Tables 6 and 7).
The negative binomial regression models are formulated as follows:

$$
\begin{gathered}
\log (\mathrm{Yc})=9.8196+0.0165 \mathrm{X} 1-0.0009 \mathrm{X} 2+0.0 .0363 \mathrm{X} 3+0.5538 \mathrm{X} 4-0.0058 \mathrm{X} 5-0.1072 \mathrm{X} 6-0.6046 \mathrm{X} 7 \\
\log (\mathrm{Yd})=1.7414-0.0626 \mathrm{X} 1-0.0015 \mathrm{X} 2+0.7034 \mathrm{X} 3+0.0711 \mathrm{X} 4-0.0055 \mathrm{X} 5-0.1705 \mathrm{X} 6-0.6480 \mathrm{X} 7
\end{gathered}
$$

Yc and Yd represents the counts of COVID-19related cases and deaths respectively. $\mathrm{X} 1$ is population ages 65 and above (\% of total population). X2 is the population density. $\mathrm{X} 3$ is the health expenditure of GDP. X4 is NCD-caused deaths (\% of total deaths). $\mathrm{X} 5$ is healthcare workforce per capita. X6 is hospital beds per capita. X7 is the Democracy Index.

In subgroup analysis, negative binomial regressions for deaths counts show that health expenditure as a percentage of GDP has a significant coefficient of 0.7034 with deaths of COVID-19. We estimate that for each one-unit increase in health expenditure as a percentage of GDP, the log count of the COVID-19-related deaths increases by 0.7034 person. In contrast, DI has a coefficient of 0.6480 which indicates that for each one-unit increase in DI, the log count of deaths decreases by 0.6480 person. In addition, regression analysis for cases suggests that the health expenditure of GDP is a significant predictor with a coefficient of 0.5538 . This result means that given a one-unit increase in health expenditure of GDP, the log count of the cases increases by 0.5538 . Furthermore, the DI has a significant negative coefficient of -0.6046 which indicates that given a one-unit increase in DI, the $\log$ count of the cases decreases by 0.6046 .
Fig. 3 Healthcare workforce per 10,000 population and hospital beds per 1000 population distribution by regime type. a $x$ axis represents the four types of regimes in the order of

"Authoritarian Regime," "Hybrid Regime," "Flawed Democracy," and "Full Democracy," $y$-axis indicates healthcare workforce per 10,000 population. b $y$-axis indicates hospital beds per 1000 population

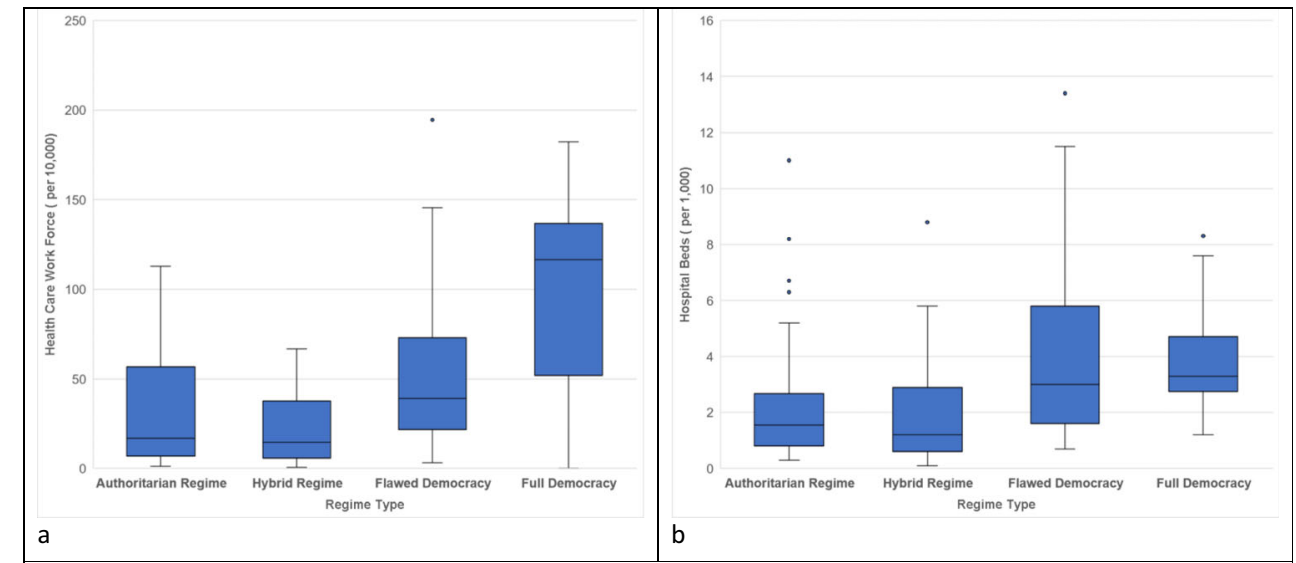


Table 5 Multiple linear regression results of the association between predictors and case fatality rate of COVID19 in high-income countries $(N=$ 47)

\begin{tabular}{lll}
\hline Variables & $\begin{array}{l}\text { Model 2 } \\
\text { Parameter estimate }(\beta)\end{array}$ & $\begin{array}{l}\left(R^{2}=0.3857\right) \\
P \text { value }\end{array}$ \\
\hline Population ages 65 years and above $^{\mathrm{a}}$ & 0.0085 & 0.0249 \\
Population density $^{\mathrm{b}}$ & 0.0002 & 0.6866 \\
Health expenditure of GDP $^{\mathrm{c}}$ & 0.0068 & 0.1313 \\
NCD-caused deaths $^{\mathrm{d}}$ & -0.0024 & 0.8982 \\
Healthcare workforce $^{\mathrm{e}}$ & 0.0023 & 0.2680 \\
Hospital beds $^{\mathrm{f}}$ & -0.0075 & 0.0056 \\
Democracy Index $^{\mathrm{g}}$ & -0.0019 & 0.0490
\end{tabular}

${ }^{\text {a }}$ Percentage of the population ages 65 and above

${ }^{\mathrm{b}}$ Population per $\mathrm{km}^{2}$ of the country's surface area

${ }^{\mathrm{c}}$ Health expenditure as a percentage of the gross domestic product

${ }^{\mathrm{d}}$ Percentage of deaths caused by non-communicable diseases of total deaths

${ }^{\mathrm{e}}$ Total number of medical doctors, nurses, and midwives per 10,000 population

${ }^{\mathrm{f}}$ Number of hospital beds per 1000 population

${ }^{\mathrm{g}}$ Democracy Index score $(0-10)$

Parameter estimate $(\beta)$, regression coefficient

\section{Discussion}

When adjusting predictors included in this analysis, the DI score was not statistically related to the case fatality of COVID-19 among the 148 countries. However, after stratifying by income levels, the DI score was negatively associated with the case fatality rate of COVID-19 patients within the 47 high-income countries. This finding highlighted an association between level of democracy according to the Democracy Index 2019 and the capacity of high-income

Table 6 Negative binomial regression estimated association between predictors and cases in high-income countries $(N=47)$

\begin{tabular}{lll}
\hline Variables & Odds ratio & 95\% CI \\
\hline Population ages 65 and above $^{\mathrm{a}}$ & 1.0166 & $(0.8523,1.2126)$ \\
Population density $^{\mathrm{b}}$ & 0.9991 & $(0.9976,1.0006)$ \\
Health expenditure of GDP $^{\mathrm{c}}$ & 1.7398 & $(1.2872,2.3517)$ \\
NCD-caused deaths $^{\mathrm{d}}$ & 1.0370 & $(0.9132,1.1776)$ \\
Healthcare workforce $^{\mathrm{e}}$ & 0.9942 & $(0.9848,1.0037)$ \\
Hospital beds $^{\mathrm{f}}$ & 0.8983 & $(0.7288,1.1072)$ \\
Democracy Index $^{\mathrm{g}}$ & 0.5463 & $(0.3660,0.8155)$
\end{tabular}

${ }^{a}$ Percentage of the population ages 65 and above

${ }^{\mathrm{b}}$ Population per $\mathrm{km}^{2}$ of the country's surface area

${ }^{\mathrm{c}}$ Health expenditure as a percentage of the gross domestic product

${ }^{\mathrm{d}}$ Percentage of deaths caused by non-communicable diseases of total deaths

${ }^{\mathrm{e}}$ Total number of medical doctors, nurses, and midwives per 10,000 population

${ }^{\mathrm{f}}$ Number of hospital beds per 1000 population

${ }^{g}$ Democracy Index score (0-10) countries to legitimate sufficient public health response to an urgent health crisis like COVID-19 in high-income countries.

Based on the multiple linear regression analysis, population density was not associated with case fatality rates in 148 countries. Scholars have argued that high population density contributed to the transmission of COVID-19 (Rashed et al. 2020). However, urgent lockdown and social distance policies, especially in authoritarian countries, and mandated measures to their citizens might reduce the possibility of humanto-human transmission (HHT) (Tian et al. 2020). Although the

Table 7 Negative binomial regression estimated association between predictors and deaths in high-income countries $(N=47)$

\begin{tabular}{lll}
\hline Variables & Odds ratio & 95\% CI \\
\hline Population ages 65 and above $^{\mathrm{a}}$ & 1.0646 & $(0.8538,1.3275)$ \\
Population density $^{\mathrm{b}}$ & 0.9985 & $(0.9969,1.0002)$ \\
Health expenditure of GDP $^{\mathrm{c}}$ & 2.0206 & $(1.3797,2.9593)$ \\
NCD-caused deaths $^{\mathrm{d}}$ & 1.0737 & $(0.9127,1.2631)$ \\
Healthcare workforce $^{\mathrm{e}}$ & 0.9945 & $(0.9834,1.0057)$ \\
Hospital beds $^{\mathrm{f}}$ & 0.8433 & $(0.6691,1.0628)$ \\
Democracy Index $^{\mathrm{g}}$ & 0.5231 & $(0.3441,0.7952)$ \\
\hline
\end{tabular}

${ }^{\text {a }}$ Percentage of the population ages 65 and above

${ }^{\mathrm{b}}$ Population per $\mathrm{km}^{2}$ of the country's surface area

${ }^{\mathrm{c}}$ Health expenditure as a percentage of the gross domestic product

${ }^{\mathrm{d}}$ Percentage of deaths caused by non-communicable diseases of total deaths

${ }^{\mathrm{e}}$ Total number of medical doctors, nurses, and midwives per 10,000 population

${ }^{\mathrm{f}}$ Number of hospital beds per 1000 population

${ }^{\mathrm{g}}$ Democracy Index score (0-10) 
DI variable was not a significant predictor in the first multiple linear regression model, those authoritarian countries are more likely to legitimate emergent and effective public health measures announced by the central governments. Like driving under the influence (DUI) is illegal because of threatening other people's lives and safety, temporarily mandated measures responding to pandemics should be separated from suppression of citizens' democracy and freedom. Otherwise, the time for countries weighing the trade-off between mandates and suggestive measures would possibly lose the critical point of mitigation.

This empirical study fills the gap of current knowledge that concentrates on the extent to which the health care system and health policy can mitigate the spreading of COVID-19 across countries and regions (Douglas et al. 2020; Parodi and Liu 2020). Although some scholars have debated the association between deaths and healthcare resource distribution, such as personal protective equipment (PPE) allocation in Italy (Lapolla et al. 2020), little is known about the influence of healthcare human resources. The healthcare workforce did not relate to the case fatality rate of COVID-19. One explanation may be due to the overwhelming number of patients and the saturation of healthcare systems by the influx of patients. As the pandemic has continued to develop through 2021, health professionals have faced another unprecedented challenge: an overwhelming number of patients and more reproductive variants. Determining the healthcare system's constraints and the correlated factors to be examined in future research is critical. For instance, one case study of the USA evaluated and concluded that healthcare resource distribution equity could enhance the effectiveness of protecting citizens against the infection and deaths from COVID-19 (Bartsch et al. 2020; Parodi and Liu 2020). However, democratic countries neglected to implement long-term, sustainable strategies to reinforce the healthcare system to manage the abrupt shift in demand in terms of the healthcare workforce and resources caused by the COVID-19 crisis.

The result was as expected: a higher percentage of population ages 65 and above was positively correlated with higher case fatality rates among 148 countries. Therefore, this confirms that coronavirus is more fatal for the aged population regardless of race (Dowd et al. 2020). Unexpectedly, the percentage of deaths caused by non-communicable disease of total deaths did not reach statistical significance. The previous research suggested that the clinical outcomes of the patients with comorbidities are worse than those without underlying health conditions (Guan et al. 2020). However, the most recent studies claim that, at the peak of the pandemic, comorbidities did not have associations with the mortality of COVID-19. While diabetes, cardiovascular diseases, and hypertension are the most frequent comorbidities diagnosed among COVID-19 patients who are more likely to develop severe disease, the current study does not provide clear evidence that the prevalence of comorbidities at the country level increases overall risk of deaths from COVID-19 (Bajgain et al. 2020; Novelli et al. 2020). Although underlying health conditions often exacerbate a person's illness from the novel coronavirus, the interpretation that comorbidities relate to death rather than the viral infection is incorrect.

One surprising result was the positive relationship between the health expenditure as a percentage of GDP and the case fatality rates of COVID-19. The patients with COVID-19 related did not benefit from living in countries with higher health expenditure of GDP. This result is different from those in previous reports (Coccia 2021). The health expenditure of GDP contains several divisions of investment while countries differ dramatically on a budget of preventive medicine, clinical medicine, and research and development of cutting-edge equipment (Jakovljevic and Getzen 2016). Healthcare capacity or functionality from an infectious disease perspective may be sensitive to decisions about allocation well in advance of the pandemic. For high-income countries, chronic diseases are classified as a top priority instead of infectious diseases (Beaglehole et al. 2007). Countries spending more on health expenditure are those with a higher proportion of senior citizens. On the other hand, countries with higher healthcare costs are more likely to test their citizens and report the confirmed cases and deaths.

Findings from the analysis of high-income countries support our hypothesis and indicate a negative association between democracy and health outcomes of COVID-19, which coincides with previous studies on the relationship between democracy, maternal and infant mortality rates, and HIV/AIDS prevalence (Bollyky et al. 2019; Franco et al. 2004; Gizelis 2009). Increasing empirical analyses show that pandemic-related factors cannot solely explain the considerable variation of outcomes across countries. Engler and colleagues suggested that the established democratic principles before the pandemic makes democratic governments reluctant to implement mandatory health policies (Engler et al. 2021). Thus, we believe that the DI explains the variation of countries' responses to COVID-19; that is, the higher the democracy level, the less the restriction of citizens' freedoms and the national public health policy. As a result, democratic governments more likely respond with selfcontrol public health measures without stringent interventions (Cheibub et al. 2020; Engler et al. 2021). These may lead to increased transmission, infections, and deaths.

The results suggest that democracy might be a risk factor in high-income countries. The hospital beds, healthcare workforce, and health expenditure of GDP may be protective factors. Because of the variations across countries, we suspect that some potential factors and mechanisms are likely mediating the predictors and health outcomes. Future research in this field is needed to evaluate the effect of democracy in two-way directions. The pandemic may also affect the level of democracy across countries. 
The main findings of this study are subject to several limitations. First, due to the self-reported confirmed cases and deaths collected from different countries, the open-use datasets provided by international institutions and organizations may have variations of measurements across countries. Second, the confirmed cases of COVID-19 likely are underestimated because of the capacity of testing for each country and scarcity of medical resources, particularly within some low-income countries; for example, the PCR testing kits will limit the numerator of the morbidity rate (Beaglehole et al. 2007). Conversely, the mortality of COVID-19 is likely to be overestimated because of excess deaths. The DI data may include bias with respect to the instruments and evaluations which are limited to epidemiological research. Third, data collected for the original goal or purpose might be difficult to utilize to respond to different research questions. Finally, because the current research employed a nonexperimental cross-sectional study design, any demonstrated associations cannot be assumed to be causal. There are many alternative explanations for the demonstrated associations and also substantial heterogeneity among countries with both democratic and authoritarian governments. Thus, it is entirely likely that factors other than democracy may explain the observed variability in COVID-19 mortality. The stratified data within low-income, lower-middle-income, and highermiddle-income countries did not show any patterns or relations, possibly due to the relevance of predictors and variations among different levels of incomes. However, future research could leverage a retrospective research design to elucidate unanswered questions in this study.

\section{Conclusion}

This multicountry study suggests that health expenditure of GDP, hospital beds per capita, and population ages 65 and above were associated with the case fatality rates of COVID-19. However, none of these can be quickly modified in the setting of a pandemic, so prior preparation with excess capacity may be warranted. To our surprise, a lower Democracy Index score (more authoritarian government) was strongly and independently associated with decreased numbers of cases and decreased case fatality rate from COVID-19, suggesting that the ability to enforce health mandates on the population may be the most important element in response to a pandemic. Countries with a high Democracy Index score should consider policies that allow the healthcare equivalent of martial law so that any future pandemic can be controlled more effectively.

Acknowledgements Not applicable.
Author contribution LY and JCG conceived and designed the project. LY performed data searching and collection. LY, MHL, and JYW analyzed the data. JCG, SCH, JYW, MHL, and JEB revised the manuscript. LY wrote the manuscript. All authors revised and approved the manuscript.

Funding The authors received no financial support for the research, authorship, and publication of this article.

Data availability The datasets used and or analyzed during the current study are available from the corresponding author on reasonable request.

\section{Declarations}

Ethics approval and consent to participate Not applicable.

Consent for publication Not applicable.

Competing interests The authors declare no competing interests.

\section{References}

Adams JG, Walls RM (2020) Supporting the health care workforce during the COVID-19 global epidemic. JAMA 323:1439-1440

Albitar O, Ballouze R, Ooi JP, Sheikh Ghadzi SM (2020) Risk factors for mortality among COVID-19 patients. Diabetes Res. Clin. Pract. 166:108293

Alhassan GN, Adedoyin FF, Bekun FV, Agabo TJ (2020): Does life expectancy, death rate and public health expenditure matter in sustaining economic growth under COVID-19: Empirical evidence from Nigeria? Journal of Public Affairs, e2302

Bajgain KT, Badal S, Bajgain BB, Santana MJ (2020): Prevalence of comorbidities among individuals with COVID-19: A rapid review of current literature. Am. J. Infect. Control

Bartsch SM, Ferguson MC, McKinnell JA, O'Shea KJ, Wedlock PT, Siegmund SS, Lee BY (2020) The potential health care costs and resource use associated with COVID-19 in the United States. Health Aff. (Millwood) 39:927-935

Bavel JJV, Baicker K, Boggio PS, Capraro V, Cichocka A, Cikara M, Crockett MJ, Crum AJ, Douglas KM, Druckman JN, Drury J, Dube O, Ellemers N, Finkel EJ, Fowler JH, Gelfand M, Han S, Haslam SA, Jetten J et al (2020) Using social and behavioural science to support COVID-19 pandemic response. Nature Human Behaviour 4:460-471

Beaglehole R, Ebrahim S, Reddy S, Voûte J, Leeder S (2007) Prevention of chronic diseases: a call to action. The Lancet 370:2152-2157

Besley T, Kudamatsu M (2006) Health and democracy. Am. Econ. Rev. 96:313-318

Blum J, Dorn F, Heuer A (2021) Political institutions and health expenditure. Int. Tax Public Finance 28:323-363

Bollyky TJ, Templin T, Cohen M, Schoder D, Dieleman JL, Wigley S (2019) The relationships between democratic experience, adult health, and cause-specific mortality in 170 countries between 1980 and 2016: an observational analysis. The Lancet 393:1628-1640

Brownlea A (1981) From public health to political epidemiology. Soc. Sci. Med. D 15:57-67

Cheibub JA, Hong JYJ, Przeworski A (2020): Rights and deaths: government reactions to the pandemic. Available at SSRN 3645410

Coccia M (2021): High health expenditures and low exposure of population to air pollution as critical factors that can reduce fatality rate in COVID-19 pandemic crisis. Environ. Res., 111339 
Coşkun H, Yıldırım N, Gündüz S (2021) The spread of COVID-19 virus through population density and wind in Turkey cities. Sci. Total Environ. 751:141663

Douglas M, Katikireddi SV, Taulbut M, McKee M, McCartney G (2020) Mitigating the wider health effects of covid-19 pandemic response. BMJ 369:m1557

Dowd JB, Andriano L, Brazel DM, Rotondi V, Block P, Ding X, Liu Y, Mills MC (2020) Demographic science aids in understanding the spread and fatality rates of COVID-19. Proceedings of the National Academy of Sciences 117:9696-9698

Driggin E, Madhavan MV, Bikdeli B, Chuich T, Laracy J, Biondi-Zoccai G, Brown TS, Der Nigoghossian C, Zidar DA, Haythe J (2020) Cardiovascular considerations for patients, health care workers, and health systems during the COVID-19 pandemic. J. Am. Coll. Cardiol. 75:2352-2371

Economist Intelligence Unit (2020a): Democracy Index 2019 A year of democratic setbacks and popular protest

Economist Intelligence Unit (2020b): Democracy Index 2019. A year of democratic setbacks and popular protest.

Engler S, Brunner P, Loviat R, Abou-Chadi T, Leemann L, Glaser A, Kübler D (2021): Democracy in times of the pandemic: explaining the variation of COVID-19 policies across European democracies. West European Politics, 1-22

Espen Beer Prydz DW (2019): Classifying countries by income

Fidler DP (2004) Germs, governance, and global public health in the wake of SARS. The Journal of Clinical Investigation 113:799-804

Franco Á, Álvarez-Dardet C, Ruiz MT (2004) Effect of democracy on health: ecological study. BMJ 329:1421-1423

Gizelis T-I (2009) Wealth alone does not buy health: Political capacity, democracy, and the spread of AIDS. Political Geography 28:121131

Greer SL, King EJ, da Fonseca EM, Peralta-Santos A (2020): The comparative politics of COVID-19: The need to understand government responses. Glob Public Health, 1-4

Grossman G, Kim S, Rexer JM, Thirumurthy H (2020): Political partisanship influences behavioral responses to governors' recommendations for COVID-19 prevention in the United States, pp. 2414424153

Gu T, Yao L, Meng X, Graff JC, Thomason D, Li J, Dong W, Jiao Y, Aleya L, Maida M (2020): A cost-effective plan for global testing-an infection rate stratified, algorithmic guided, multiple-level, continuously pooled testing strategy. Sci. Total Environ., 144251

Guan W-J et al (2020) Comorbidity and its impact on 1590 patients with COVID-19 in China: a nationwide analysis. Eur. Respir. J. 55: 2000547

Ho FK, Petermann-Rocha F, Gray SR, Jani BD, Katikireddi SV, Niedzwiedz CL, Foster H, Hastie CE, Mackay DF, Gill JM (2020) Is older age associated with COVID-19 mortality in the absence of other risk factors? General population cohort study of 470,034 participants. PLoS One 15:e0241824

Honjo K (2004) Social epidemiology: definition, history, and research examples. Environ. Health Prev. Med. 9:193-199

Jakovljevic M, Getzen TE (2016) Growth of global health spending share in low and middle income countries. Front. Pharmacol. 7

Johns Hopkins Coronavirus Resource Center (2020): COVID-19 dashboard by the center for systems science and engineering (CSSE) at Johns Hopkins University

Johns Hopkins Coronavirus Resource Center (2021): COVID-19 dashboard by the center for systems science and engineering (CSSE) at Johns Hopkins University

Karabulut G, Zimmermann KF, Bilgin MH, Doker AC (2021) Democracy and COVID-19 outcomes. Econ. Letters 203:109840

Kelly H, Cowling BJ (2013a) Case fatality: rate, ratio, or risk? Epidemiology 24:622-623
Kelly H, Cowling BJ (2013b) Case fatality: rate, ratio, or risk? Epidemiology 24:622-623

Kluge HHP, Wickramasinghe K, Rippin HL, Mendes R, Peters DH, Kontsevaya A, Breda J (2020) Prevention and control of noncommunicable diseases in the COVID-19 response. The Lancet 395:1678-1680

Kraemer MUG, Yang C-H, Gutierrez B, Wu C-H, Klein B, Pigott DM, du Plessis L, Faria NR, Li R, Hanage WP, Brownstein JS, Layan M, Vespignani A, Tian H, Dye C, Pybus OG, Scarpino SV (2020) The effect of human mobility and control measures on the COVID-19 epidemic in China. Science 368:493-497

Lapolla P, Mingoli A, Lee R (2020) Deaths from COVID-19 in healthcare workers in Italy - what can we learn? Infect. Control Hosp. Epidemiol.:1-2

Mackenbach JP, Hu Y, Looman CWN (2013) Democratization and life expectancy in Europe, 1960-2008. Soc. Sci. Med. 93:166-175

Mazzucchelli R, Agudo Dieguez A, Dieguez Costa EM, Crespí Villarías N (2020): [Democracy and Covid-19 mortality in Europe.]. Rev. Esp. Salud Publica 94

Novelli L et al. (2020): At the peak of Covid-19 age and disease severity but not comorbidities are predictors of mortality. Covid-19 burden in Bergamo, Italy. Panminerva Med.

Pan A, Liu L, Wang C, Guo H, Hao X, Wang Q, Huang J, He N, Yu H, Lin X (2020) Association of public health interventions with the epidemiology of the COVID-19 outbreak in Wuhan, China. JAMA 323:1915-1923

Pareek M, Bangash MN, Pareek N, Pan D, Sze S, Minhas JS, Hanif W, Khunti K (2020) Ethnicity and COVID-19: an urgent public health research priority. The Lancet 395:1421-1422

Parodi SM, Liu VX (2020) From containment to mitigation of COVID19 in the US. JAMA 323:1441-1442

Rashed EA, Kodera S, Gomez-Tames J, Hirata A (2020) Influence of absolute humidity, temperature and population density on COVID19 spread and decay durations: multi-prefecture study in Japan. Int. J. Environ. Res. Public Health 17:5354

Safaei J (2006) Is democracy good for health? Int. J. Health Serv. 36:767786

Sanyaolu A, Okorie C, Marinkovic A, Patidar R, Younis K, Desai P, Hosein Z, Padda I, Mangat J, Altaf M (2020) Comorbidity and its impact on patients with COVID-19. SN Comprehensive Clinical Medicine 2:1069-1076

Sen-Crowe B, Sutherland M, McKenney M, Elkbuli A (2021) A closer look into global hospital beds capacity and resource shortages during the COVID-19 pandemic. J. Surg. Res. 260:56-63

Shandra JM, Shandra CL, London B (2010) Debt, structural adjustment, and non-governmental organizations: a cross-national analysis of maternal mortality. Journal of World-Systems Research:217-245

Tian H, Liu Y, Li Y, Wu CH, Chen B, Kraemer MUG, Li B, Cai J, Xu B, Yang Q, Wang B, Yang P, Cui Y, Song Y, Zheng P, Wang Q, Bjornstad ON, Yang R, Grenfell BT et al (2020) An investigation of transmission control measures during the first 50 days of the COVID-19 epidemic in China. Science 368:638-642

World Bank (2020): World Bank Open Data

World Health Organization (2020a): Coronavirus disease (COVID-19)

World Health Organization (2020b): WHO coronavirus disease (COVID19) dashboard

World Health Organization (2020c): The Global Health Observatory

Yan B, Zhang X, Wu L, Zhu H, Chen B (2020) Why do countries respond differently to COVID-19? A comparative study of Sweden, China, France, and Japan. The American Review of Public Administration 50:762-769

Publisher's note Springer Nature remains neutral with regard to jurisdictional claims in published maps and institutional affiliations. 